\title{
Acetaminophen-Induced Liver Injury Alters Expression and Activities of Cytochrome P450 Enzymes in an Age-Dependent Manner in Mouse Liver $^{\circledR}$
}

\author{
Yifan Bao, Pei Wang, Xueyan Shao, Junjie Zhu, Jingcheng Xiao, Jian Shi, Lirong Zhang, \\ Hao-Jie Zhu, (DXiaochao Ma, @José E. Manautou, and ๑Xiao-bo Zhong
}

Department of Pharmaceutical Sciences, School of Pharmacy, University of Connecticut, Storrs, Connecticut (Y.B., P.W., X.S., J.E.M., X.Z.); Department of Pharmacology, School of Basic Medical Sciences, Zhengzhou University, Zhengzhou, Henan, China (P.W., L.Z.); Department of Pharmaceutical Sciences, School of Pharmacy, University of Pittsburgh, Pittsburgh, Pennsylvania (J.Z., X.M.); and Departments of Pharmaceutical Sciences (J.X.) and Clinical Pharmacy (J.S., H.-J.Z.), College of Pharmacy, University of Michigan, Ann Arbor, Michigan

Received October 7, 2019; accepted February 18, 2020

\section{ABSTRACT}

Drug-induced liver injury (DILI) is a global medical problem. The risk of DILI is often related to expression and activities of drugmetabolizing enzymes, especially cytochrome P450s (P450s). However, changes on expression and activities of P450s after DILI have not been determined. The aim of this study is to fill this knowledge gap. Acetaminophen (APAP) was used as a model drug to induce DILI in C57BL/6J mice at different ages of days 10 (infant), 22 (child), and 60 (adult). DILI was assessed by levels of alanine aminotransferase and aspartate aminotransferase in plasma with a confirmation by H\&E staining on liver tissue sections. The expression of selected P450s at mRNA and protein levels was measured by real-time polymerase chain reaction and liquid chromatography-tandem mass spectrometry, respectively. The activities of these P450s were determined by the formation of metabolites from probe drugs for each P450 using ultraperformance liquid chromatography-quadrupole time of flight mass spectrometry. DILI was induced at mild to severe levels in a dose-dependent manner in 200,300, and $400 \mathrm{mg} / \mathrm{kg}$ APAP-treated groups at child and adult ages, but not at

the infant age. Significantly decreased expression at mRNA and protein levels as well as enzymatic activities of CYP2E1, 3A11, 1A2, and 2C29 were found at child and adult ages. Adult male mice were more susceptible to APAP-induced liver injury than female mice with more decreased expression of P450s. These results suggest that altered levels of P450s in livers severely injured by drugs may affect the therapeutic efficacy of drugs, which are metabolized by P450s, more particularly for males.

\section{SIGNIFICANCE STATEMENT}

The current study in an animal model demonstrates that acetaminophen-induced liver injury results in decreased expression and enzyme activities of several examined drug-metabolizing cytochrome P450s (P450s). The extent of such decreases is correlated to the degree of liver injury severity. The generated data may be translated to human health for patients who have drug-induced liver injury with decreased capability to metabolize drugs by certain P450s.

\section{Introduction}

Drug therapy is an important part of the current practical medicine to treat human diseases, but has a potential risk to develop drug-induced liver injury (DILI). The incidence data in various populations in Europe

This study was partly supported by the National Institutes of Health $(\mathrm{NIH})$ National Institute of General Medical Sciences [Grant R01GM-118367 to X.Z.]; the National Institute of Allergy And Infectious Diseases [Grant R01 Al131983 to X.M.]; and the NIH National Heart, Lung, and Blood Institute [Grant R01HL126969 to H.-J.Z.]. This study was also partly supported by the Institute for System Genomics at the University of Connecticut (to X.Z.). P.W. was a visiting scholar supported by the China Scholarship Council [Grant 201707040007].

https://doi.org/10.1124/dmd.119.089557.

S This article has supplemental material available at dmd.aspetjournals.org.
(Sgro et al., 2002), North America (Bell and Chalasani, 2009; Leise et al., 2014; Vega et al., 2017), and Asia (Shen et al., 2019) indicate that there are approximately 10-24 new cases of DILI per 100,000 persons each year. In the over 7.7 billion global individuals in 2019 documented by the World Population Prospects of the United Nations, the estimated total cases of DILI may reach to 0.7-1.4 million worldwide. More than 900 drugs have been implicated in causing DILI (Larrey, 2002; Maddrey, 2005; Hoofnagle et al., 2013). The current drug therapy approaches do not specially consider whether patients with DILI have different efficacy and risks for adverse reactions in comparison with patients who do not have DILI.

Efficacy and adverse reactions of drug therapy largely rely on drug metabolism in liver. The role of drug metabolism in causing DILI has been defined (Corsini and Bortolini, 2013). Especially, drug metabolism

ABBREVIATIONS: AILI, APAP-induced liver injury; ALT, alanine aminotransferase; APAP, acetaminophen; AST, aspartate aminotransferase; BSA, bovine serum albumin; $\mathrm{CHZ}$, chlorzoxazone; DILI, drug-induced liver injury; EFV, efavirenz; GAPDH, glyceraldehyde-3-phosphate dehydrogenase; LC-MS/MS, liquid chromatography-tandem mass spectrometry; MDZ, midazolam; miRNA, microRNA; NAPQI, N-acetyl-para-benzo-quinone imine; P450, cytochrome P450; RSF, resorufin; RSG, rosiglitazone; UNL, upper limit of normal level; UPLC-QTOFMS, ultraperformance liquid chromatography-quadrupole time of flight mass spectrometry. 
by phase I enzymes of cytochrome P450s (P450s) can lead to formation of toxic metabolites in liver (Pasanen et al., 1995; Brewer and Chen, 2017; Hassan et al., 2018). One such example is P450-mediated metabolism of acetaminophen (APAP), a popular analgesic drug. APAP is the leading cause of acute liver failure in the United States (Fontana, 2008; Yoon et al., 2016). APAP-induced liver injury (AILI) is mainly due to the formation of a toxic metabolite of $\mathrm{N}$-acetyl-para-benzoquinone imine (NAPQI) in liver during APAP metabolism by CYP2E1, 1A2, and 3A4 (Dahlin et al., 1984; Yoon et al., 2016). Increased enzyme activities of CYP2E1, 1A2, and 3A4 in liver can lead to increased susceptibility to AILI.

A knowledge gap exists in the current practice of pharmacotherapy on whether injured liver caused by DILI alters drug metabolism by P450s, resulting in changes in efficacy and adverse reactions of drug therapy. We hypothesize that DILI results in altered hepatic expression and activities of several P450s. To test the hypothesis, the current study used APAP as a model drug and mouse as the animal model to systematically determine the impact of AILI on expression and activities of P450s in liver at different ages. APAP is the leading cause of DILI worldwide, and its toxicity is dose-dependent (Bunchorntavakul and Reddy, 2013). Comparing in vivo and in vitro models for AILI, the mouse model has the most similarity in toxicity initiation with human primary hepatocytes, and toxic doses have been well defined (Jaeschke et al., 2014; Xie et al., 2014). Mouse CYP3A11 contributes to convert APAP to NAPQI (Guo et al., 2004). In consideration of the changes of expression and activities of $\mathrm{P} 450 \mathrm{~s}$ in mouse liver during postnatal maturation (Hart et al., 2009; Peng et al., 2012), we hypothesized that the consequence of APAP treatment on $\mathrm{P} 450$ expression is in an age-dependent manner. The current study determined expression and activities of various key drugmetabolizing P450s (CYP1A2, 2B10, 2C29, 2E1, and 3A11) in mouse liver at different ages of postnatal day 10 (infant), 22 (child), or 60 (adult) with different levels of AILI caused by exposure to different doses of APAP.

\section{Materials and Methods}

Chemicals and Reagents. PBS, APAP, resorufin (RSF), and midazolam (MDZ) were purchased from Sigma-Aldrich (St. Louis, MO). Buffered formalin (10\%) was purchased from Fisher Science (Fair Lawn, NJ). Efavirenz (EFV) was purchased from TCI American (Portland, OR). 1-OH-MDZ and 8-OH-EFV were purchased from Toronto Research Chemicals (Ontario, Canada). Rosiglitazone (RSG), demethyl-RSG, chlorzoxazone (CHZ), 7-ethoxy-RSF, and 6-OH-CHZ were obtained from Cayman Chemical (Ann Arbor, MI).

Animals and Drug Treatment. C57BL/6J mice were obtained from Jackson Laboratory (Bar Harbor, ME). Mice were bred under standard conditions and housed in compliance with the animal care guidelines outlined by the American Association for Animal Laboratory Sciences in the Animal Resources Facility at the University of Connecticut. All animal procedures were approved by the University of Connecticut's Institutional Animal Care and Use Committee. At the age of 6 weeks, mice were set up into breeding pairs to produce sufficient mice at postnatal day 10 (infant), 22 (child), or 60 (adult). Given the fact that male mice are more susceptible to APAP than female mice (Dai et al., 2006), male mice were used to investigate the role of age- and dose-dependency in AILI in the current study. In brief, male mice at different ages (postnatal day 10, 22, or 60) were intraperitoneally administered a single dose of APAP $(200,300$, or $400 \mathrm{mg} / \mathrm{kg}$ ) or PBS (vehicle control). To study the different effects of AILI by sex, both male and female mice at day 60 after birth were included. Before 16 hours and after 8 hours of APAP dosing, mice at days 22 and 60 were fasted with free access to water to avoid food-induced changes in liver genes (Gavito et al., 2016). All the mice were sacrificed at 24 hours after APAP treatment to collect blood and liver samples. A part of the liver was fixed with $10 \%$ formalin buffer for histopathological analysis. Remaining other liver tissues were snap frozen in liquid nitrogen and then stored at $-80^{\circ} \mathrm{C}$ for further gene expression analysis.

Plasma Alanine Aminotransferase and Aspartate Aminotransferase Assay. Blood samples were collected in anticoagulant-coated tubes (Fisher
Scientific) and centrifuged at $3000 \mathrm{~g}$ for 10 minutes to obtain plasma. Levels of plasma alanine aminotransferase (ALT) and aspartate aminotransferase (AST) were measured as biomarkers of hepatocellular injury. Scientific AST/GOT and ALT/GPT Reagents from Thermo Fisher (Waltham, MA) were used to determine AST and ALT levels, respectively, with a method described previously (Rudraiah et al., 2014). A BioTek Power Wave X Spectrophotometer (BioTek, Winooski, VT) was used to analyze the samples.

H\&E Staining. Liver samples were fixed with $10 \%$ buffered formalin and kept at $4^{\circ} \mathrm{C}$ for $\mathrm{H} \& \mathrm{E}$ staining. The embedding and slicing process of $\mathrm{H} \& \mathrm{E}$ staining was performed by the Connecticut Veterinary Medical Diagnostic Laboratory (http://cvmdl.uconn.edu/). Images were taken by a phase-contrast microscope with a $20 \times$ objective lens. The scale bars were added by ImageJ software.

Quantification of P450 mRNAs by Real-Time Polymerase Chain Reaction. Total RNAs were isolated from frozen liver tissues using a TRIzol reagent (Life Technologies, Guilford, CT) according to the manufacturer's protocol. RNA concentrations were measured by a NanoDrop spectrophotometer from NanoDrop Technologies (Wilmington, DE) at $260 \mathrm{~nm}$, and mRNA integrity was evaluated using an Agilent 2200 Tape Station from Agilent Technologies (Santa Clara, CA). To obtain cDNAs, $1 \mu \mathrm{g}$ of total mRNAs were reversely transcribed to cDNAs using an iScript cDNA Synthesis kit from Bio-Rad Laboratories (Hercules, CA). Real-time polymerase chain reactions were performed using a CFX96 Real-Time System from Bio-Rad Laboratories with the TaqMan gene expression assays for glyceraldehyde-3-phosphate dehydrogenase (GAPDH), CYP1A2, 2B10, 2C29, 2E1, and 3A11 from Thermo Fisher. Fold changes of $\mathrm{P} 450$ expression in the APAP-treated groups compared with the PBS controls at each age were calculated using the $2^{-\Delta \Delta \mathrm{Ct}}$ method with an internal normalization to GAPDH. The values were calculated for $\log _{2}$ (fold changes).

Quantification of P450 Proteins by Mass Spectrometry. Frozen liver tissues were chopped and homogenized in a PBS buffer ( $\mathrm{pH}$ 7.4). Protein samples were prepared and quantified by a previously described method (Piekos et al., 2018) using liquid chromatography-tandem mass spectrometry (LC-MS/ MS)-based approach. Briefly, liver microsomes were obtained by centrifugation. The microsomes were mixed with an internal standard bovine serum albumin (BSA) and digested by lysyl endopeptidase and trypsin. The digested peptides were extracted using Waters Oasis HLB columns (Waters Corporation, Milford, MA) and analyzed on a Triple TOF 5600+ mass spectrometer (AB Sciex, Framingham, MA) coupled with an Eksigent 2D Plus LC System (Eksigent Technologies, Dublin, CA). The proteomics data obtained from the sequential window acquisition of all theoretical mass spectra method were analyzed using the Spectronaut software (version 13.0; Biognosys AG, Schlieren, Switzerland) with the reference spectral library generated from the previous informationdependent acquisition searches (Piekos et al., 2018). The peak area of the second stage of mass spectrometry (MS2)of top three signature peptides of each protein were used for quantification with the default settings (Biognosys factory setting). Data were normalized using the "Local Normalization" strategy embedded in the Spectronaut software.

Quantification of P450 Enzyme Activities by Mass Spectrometry. S9 fractions of liver tissues were isolated by centrifugation with a previously described method (Piekos et al., 2018). To determine the enzyme activities of CYP1A2, 2B10, 2C29, 2E1, and 3A11, the reaction rates of 7-ethoxy-RSF to RSF, EFV to 8-OH-EFV, RSG to demethyl-RSG, CHZ to 6-OH-CHZ, and MDZ to $1-\mathrm{OH}-\mathrm{MDZ}$ were measured, respectively. P450 enzyme activities in the S9 fractions were determined by ultraperformance liquid chromatography-quadrupole time of flight mass spectrometry (UPLC-QTOFMS) as previously described (Tien et al., 2015).

Quantification of In Vitro Metabolism of APAP. Liver microsomes were isolated from liver tissues by centrifugation with a previously described method (Piekos et al., 2018). Microsome proteins were determined using a Qubit Protein Assay Kit (Thermo Fisher Scientific, Rockford, IL). The metabolism of APAP was initiated by adding $1 \mathrm{ml}$ of $15 \mathrm{mM} \mathrm{N}$-acetyl cysteine and $1 \mathrm{ml}$ of $3 \mu \mathrm{M}$ $\mathrm{NADPH}$ to $0.5 \mathrm{ml}$ solution containing $3 \mathrm{mg}$ microsomal proteins and incubated at $37^{\circ} \mathrm{C}$ for 10 minutes. One milliliter of $60 \mathrm{mM}$ APAP solution was added subsequently and incubated at $37^{\circ} \mathrm{C}$ for 30 minutes. The reaction was terminated by adding $3 \mathrm{ml}$ of ice-cold methanol. After centrifugation at $2800 \mathrm{~g}$ for 30 minutes and filteration through a $0.22 \mu \mathrm{m}$ Millipore filter, a $20-\mu l$ aliquot was injected into a Shimadzu CTO-20A/2-AC HPLC-UV system for quantification of APAP. Chromatographic separation of metabolites was performed on an Agilent 5 
HC-C18(2) column (4.6 × 250 mm, $5 \mu \mathrm{m}$; Agilent Technologies $)$ Mobile phase A consisted of $1 \%$ glacial acetic acid in water, and mobile phase B was methanol. The flow rate of the mobile phase was $0.80 \mathrm{ml} / \mathrm{min}$, and the column temperature was maintained at $25^{\circ} \mathrm{C}$. The absorbance wavelength of photodiode array detector was $254 \mathrm{~nm}$. The rate of APAP metabolism was calculated by the decreased amount of APAP divided by the amount of microsomal proteins within the reaction time.

Quantification of Total Liver Proteins. A 5-mg frozen liver sample was homogenized with $300 \mu \mathrm{l}$ radioimmunoprecipitation assay (RIPA) buffer (Thermo Fisher Scientific). After centrifugation at $14,000 \mathrm{~g}$ for 30 minutes at $4^{\circ}$ $\mathrm{C}$, total protein concentration in the supernatant was determined by a Qubit Protein Assay Kit (Thermo Fisher Scientific).

Statistical Analysis. The data are presented as means \pm S.D. Statistical analysis was performed by one-way ANOVA with Dunnett's post hoc test using the GraphPad Prism version 7 software program from GraphPad Software, Ln. (La Jolla, CA). A value of $P<0.05$ was considered to be statistically significant.

\section{Results}

The normal ALT and AST levels in plasma of adult C57BL/6J mice collected by cardiac puncture have been defined (Fernández et al., 2010; Otto et al., 2016). In male adult mice, the upper limit of normal level (UNL) of ALT is $94 \mathrm{U} / \mathrm{l}$, whereas the UNL of AST is $122 \mathrm{U} / \mathrm{l}$. The grade of liver injury can be estimated by using the UNL of ALT and AST of mice and the grading standard of human (Hoofnagle et al., 2013). Grade 0 has a level of ALT or AST within 1.25-fold higher than the UNL. A level of ALT or AST is considered as grade 1 (mild) between 1.25- and 2.5-fold, grade 2 (moderate) between 2.5- and 5.0-fold, grade 3 (severe) between 5.0- and 10-fold, and grade 4 (extreme severe and life-threating) over 10-fold, respectively. The grading system based on ALT and AST levels for mice is summarized in Table 1. A grading system of liver injury based on Ishak scores on the morphology changes is shown in Table 2 (Goodman, 2007).

In this study, male mice at different ages (days 10, 22, or 60 after birth) were administered a single dose of $\operatorname{APAP}(200,300$, or $400 \mathrm{mg} / \mathrm{kg})$ to investigate the role of ontogeny of P450s in the severity of AILI as well as the impact of AILI on the expression of P450s. To study the sex differences, mice at day 60 were used. Briefly, both male and female mice were treated with different doses of APAP (200, 300, or $400 \mathrm{mg} / \mathrm{kg}$ ). The levels of ALT and AST and the hepatic expression of P450s were determined.

Age Affected the Severity of AILI in Male Mice. As seen in Fig. 1A, APAP treatment only led to a higher ALT level in mice at day 10 after birth at the highest dose $(400 \mathrm{mg} / \mathrm{kg})$, whereas, even with the lowest dose of APAP (200 mg/kg), plasma ALT levels in male mice dramatically increased at days 22 and 60. Moreover, higher ALT levels were observed in the groups administered higher doses of APAP in the mice at days 22 and 60 . For instance, the mice at day 60 treated with APAP at 200,300, or $400 \mathrm{mg} / \mathrm{kg}$ resulted in ALT levels of 8.57- (grade 3 injury), 10.69- (grade 4 injury), or 14.83-fold (grade 4 injury) of the UNL, respectively. When treated with the same dose of APAP, the ALT levels were found to be the highest in the mice at day 60 and the lowest in the mice at day 10. For instance, the ALT levels in the mice treated with $400 \mathrm{mg} / \mathrm{kg}$ APAP at days 10, 22, or 60 were 66, 472, or $1394 \mathrm{U} / \mathrm{l}$, respectively.

Similar findings were observed with AST values (Fig. 1B). Male mice treated with 200 or $300 \mathrm{mg} / \mathrm{kg}$ APAP showed increased AST levels at days 22 and 60, but not at day 10. APAP treatment at $400 \mathrm{mg} / \mathrm{kg}$ led to AST levels of 2.39- (grade 1 injury), 5.83- (grade 3), or 10.02-fold (grade 4) of the UNL at days 10, 22, or 60, respectively. At the same age, AILI was more severe in the group with a higher dose of APAP exposure. For the mice at day 60, APAP treatment with a dose of 200, 300 , or $400 \mathrm{mg} / \mathrm{kg}$ resulted in AILI at grade 3, 3, or 4, respectively.
H\&E staining is another standard measurement for DILI. The severity of liver injury was also confirmed by H\&E staining in this study. The characteristics of AILI is predominantly hepatocellular necrosis, featured as the abruption of the cell membranes and nuclei of hepatocytes around the central veins. Liver samples from the PBS control and $400 \mathrm{mg} / \mathrm{kg}$ APAP-treated groups with the highest ALT or AST levels were selected for staining. Representative images of the control and APAP groups are shown in Fig. 1C. No liver injury was observed in any of the control groups of any age (top row). In the APAP-treated groups (bottom row), no necrosis could be observed in the infant male mice at day 10 , but ballooning of hepatocytes was found in the child group at day 22, and large injured areas around the central veins were seen in the adult group at day 60 . The severity of the liver injury was scored by the Ishak system based on H\&E staining following the method described in Table 2. Consistent with the results in ALT or AST levels, the treatment with $400 \mathrm{mg} / \mathrm{kg}$ APAP led to the most severe injury in male mice at day 60 among the three age groups (Fig. 1C). In detail, for the infant mice at day 10 , the score in the APAP-treated group was 0 , which means no injury happened. For the child mice at day 22, the Ishak score was 2, suggesting moderate AILI. For the adult mice at day 60, APAP-treated liver had an Ishak score of 5, suggesting extremely severe AILI. The in vitro metabolism rate of APAP by liver microsomes from the mice at day 10 was significantly lower than that of the mice at day 60 , indicating that the differential severity of AILI between the ages was partly due to age-related differential metabolism of APAP, which was mainly mediated by CYP1A2, 2E1, and 3A11 (Supplemental Fig. 1).

Overall, older male mice were more susceptible to AILI than younger ones. The severity of AILI was also dose-dependent.

Effects of AILI on Expression of CYP1A2 in Mouse Liver at Different Ages. Among the three age groups, the basal mRNA expression of CYP1A2 was the highest in the mice at day 60 followed by the mice at day 22 (Fig. 2A). After the same doses of APAP treatment, the mRNA expression of CYP1A2 was also higher in the mice at days 22 and 60 than the mice at day 10 (Fig. 2A). APAP treatment significantly decreased the mRNA expression of CYP1A2 in all age groups. Compared with the age-matched controls, the mRNA expression of CYP1A2 was $85 \%$ lower in the APAP treatment mice at day 60 . Consistent with the most severe AILI at day 60, the extent of repression of CYP1A2 expression was the largest among the three ages with the same doses of APAP treatment.

The relative protein levels of CYP1A2 were measured in randomly selected male mouse livers from control $(0 \mathrm{mg} / \mathrm{kg})$ and APAP-treated $(400 \mathrm{mg} / \mathrm{kg})$ mice at each age $(n=3$ to 4$)$. Consistent with the CYP1A2 mRNA expression, the basal protein expression of CYP1A2 was also higher in older mice (Fig. 2B). Moreover, a higher protein expression of CYP1A2 was observed in the APAP-treated older age groups compared with the dose-matched mice at day 10. A significant decrease of CYP1A2 protein expression was found in the APAP-treated mice receiving $400 \mathrm{mg} / \mathrm{kg}$ at ages of days 22 and 60 in comparison with agematched controls (Fig. 2B). The changes of CYP1A2 protein were directly related to the APAP treatment because the total amount of proteins per gram liver tissue (Supplemental Fig. 2A) and microsomal recovery (Supplemental Fig. 2B) were unchanged and expression of the housekeeping protein GAPDH was unaffected by APAP treatment (Supplemental Fig. 2C).

The enzyme activity of CYP1A2 was determined by a UPLCQTOFMS method using the formation rates of RSF from 7-ethoxy-RSF in the liver S9 samples of four randomly selected mice from the control and $400 \mathrm{mg} / \mathrm{kg}$ APAP-treated groups. The basal activity of CYP1A2 was higher in the livers of mice at days 20 and 60 compared with the mice at day 10 (Fig. 2C). No differences in the enzyme activity of CYP1A2 were found between control and APAP-treated groups in the 
TABLE 1

Grading for liver injury

\begin{tabular}{|c|c|c|c|c|c|}
\hline & Grade 0 & Grade 1 & Grade 2 & Grade 3 & Grade 4 \\
\hline \multicolumn{6}{|l|}{ ALT level $^{\mathrm{a}}$} \\
\hline Fold $(\times$ URL) & $<1.25$ & $1.25-2.5$ & $2.6-5.0$ & $5.1-10.0$ & $>10.0$ \\
\hline Male (U/l) & $<117$ & $117-235$ & $236-470$ & $471-940$ & $>940$ \\
\hline Female (U/l) & $<110$ & $110-220$ & $221-440$ & $441-880$ & $>880$ \\
\hline \multicolumn{6}{|l|}{ AST level $^{\mathrm{a}}$} \\
\hline Fold $(\times$ URL) & $<1.25$ & $1.25-2.5$ & $2.6-5.0$ & $5.1-10.0$ & $>10.0$ \\
\hline Male (U/l) & $<152$ & $152-305$ & $306-610$ & $611-1220$ & $>1220$ \\
\hline Female (U/1) & $<220$ & $220-440$ & $441-880$ & $881-1760$ & $>1760$ \\
\hline
\end{tabular}

URL, upper reference limit.

${ }^{a}$ Value of lower limit was included, whereas value of upper limit was not included.

mice at day 10. However, after the APAP treatment, the mice at days 60 and 22 had lower CYP1A2 enzyme activity than the age-matched control groups (Fig. 2C).

Overall, APAP treatment decreased the expression of CYP1A2 at mRNA and protein levels as well as enzyme activity in the liver of mice at different ages.

Effects of AILI on Expression and Activity of CYP2B10 in Mouse Liver at Different Ages. As seen in Fig. 3A, the basal mRNA expression of CYP2B10 was lower in the mice at day 22, but higher in the mice at day 60 compared with the mice at day 10. Differential effects of APAP treatment on the expression of CYP2B10 at the three age groups were observed. Mice at day 10 receiving higher doses of APAP treatment (300 and $400 \mathrm{mg} / \mathrm{kg}$ ) exhibited decreased mRNA expression of CYP2B10 in liver, whereas increased mRNA expression of CYP2B10 by APAP was seen in the liver of mice at days 22 and 60 .

The relative protein levels of CYP2B10 were measured in randomly selected male mouse livers from control $(0 \mathrm{mg} / \mathrm{kg})$ and APAP-treated mice $(400 \mathrm{mg} / \mathrm{kg})$ at each age $(n=3$ to 4$)$. Inconsistent with CYP2B10 mRNA expression, the basal protein expression of CYP2B10 was significantly decreased in the mice at day 60 compared with the mice at day 10 (Fig. 3B). Different effects of APAP treatment on the expression of CYP2B10 were found between mRNA and protein levels. The mice at day 22 treated with APAP had lower protein expression of CYP2B10, whereas mRNA levels were higher (Fig. 3). Comparable protein levels of CYP2B10 were observed in the mice at days 10 and 60 between APAP-treated and age-matched controls (Fig. 3B).

The enzyme activity of CYP2B10 was determined by an UPLCQTOFMS-based method using the formation rates of 8-OH-EFV in liver $\mathrm{S} 9$ samples from the control and APAP-treated mice at $400 \mathrm{mg} / \mathrm{kg}$ $(n=4)$. The basal activity of CYP2B10 was higher in liver of the mice at days 22 and 60 compared with the mice at day 10 (Fig. 3C). In contrast to the effect of APAP on CYP2B10 mRNA expression, the activity of CYP2B10 was significantly decreased by APAP in the mice at day 60 (Fig. 3C). No statistical differences were seen between the control and APAP-treated mice at days 10 and 22.

Overall, APAP treatment of mice had a suppression or induction effect on the expression of CYP2B10 that is age-dependent. There is a discrepancy on the impact of APAP on CYP2B10 expression at levels of mRNA, protein, and enzyme activity.

Effects of AILI on Expression and Activity of CYP2C29 in Mouse Liver at Different Ages. As seen in Fig. 4, the expression of CYP2C29 was measured in male mice at three ages and different doses of APAP. At the ages of days 22 and 60, the basal mRNA expression of CYP2C29 was 8- and 4-fold, respectively, higher than that in the mice at day 10 (Fig. 4A). Treatment with APAP decreased the mRNA expression of CYP2C29 at each age (Fig. 4A). In the mice at day 10, mRNA level of CYP2C29 was significantly decreased in the APAP-treated mice at all three doses in comparison with the controls. For the mice at day 22, mRNA level of CYP2C29 was repressed in the mice treated with $400 \mathrm{mg} / \mathrm{kg}$ APAP compared with age-matched controls. Although the mRNA expression of CYP2C29 was decreased in a dose-dependent manner in the mice at day 22, that was still 3-fold higher after APAP treatment than the control mice at day 10 (Fig. 4A).

The relative protein levels of CYP2C29 were measured in randomly selected male mouse livers from control $(0 \mathrm{mg} / \mathrm{kg})$ and APAP-treated mice $(400 \mathrm{mg} / \mathrm{kg})$ at each age $(n=3$ to 4$)$. Consistent with the basal CYP2C29 mRNA expression, the protein expression of CYP2C29 was increased dramatically at day 22 and kept steady at day 60 compared with the mice at day 10 (Fig. 4B). APAP treatment also significantly decreased the protein expression of CYP2C29 in the mice at days 22 and 60. Although the expression of CYP2C29 at protein level was decreased

TABLE 2

Ishak evaluation system

\begin{tabular}{|c|c|c|c|c|c|c|c|}
\hline \multicolumn{2}{|c|}{$\begin{array}{l}\text { Periportal or periseptal } \\
\text { injury }\end{array}$} & \multicolumn{2}{|l|}{ Confluent necrosis } & \multicolumn{2}{|c|}{ Focal (spotty) lytic injury } & \multicolumn{2}{|l|}{ Portal inflammation } \\
\hline Absent & 0 & Absent & 0 & Absent & 0 & None & 0 \\
\hline Mild & 1 & Focal confluent necrosis & 1 & $\begin{array}{l}\text { One focus or less per } \\
10 \times \text { objective }\end{array}$ & 1 & $\begin{array}{l}\text { Mild, some or all portal } \\
\text { areas }\end{array}$ & 1 \\
\hline Mild/moderate & 2 & Zone 3 necrosis in some areas & 2 & $\begin{array}{l}\text { Two to four foci per } \\
10 \times \text { objective }\end{array}$ & 2 & $\begin{array}{l}\text { Moderate, some or } \\
\text { all portal areas }\end{array}$ & 2 \\
\hline Moderate & 3 & Zone 3 necrosis in most areas & 3 & $\begin{array}{l}\text { Five to } 10 \text { foci per } \\
10 \times \text { objective }\end{array}$ & 3 & $\begin{array}{l}\text { Moderate/marked, } \\
\text { all portal areas }\end{array}$ & 3 \\
\hline Severe & 4 & $\begin{array}{l}\text { Zone } 3 \text { necrosis }+ \text { occasional } \\
\text { portal-central }(\mathrm{P}-\mathrm{C}) \text { bridging }\end{array}$ & 4 & $\begin{array}{l}\text { More than } 10 \text { foci per } \\
10 \times \text { objective }\end{array}$ & 4 & Marked, all portal areas & 4 \\
\hline Severe & & Zone 3 necrosis + multiple P-C bridging & 5 & & & & \\
\hline Severe & & Panacinar or multiacinar necrosis & 6 & & & & \\
\hline
\end{tabular}



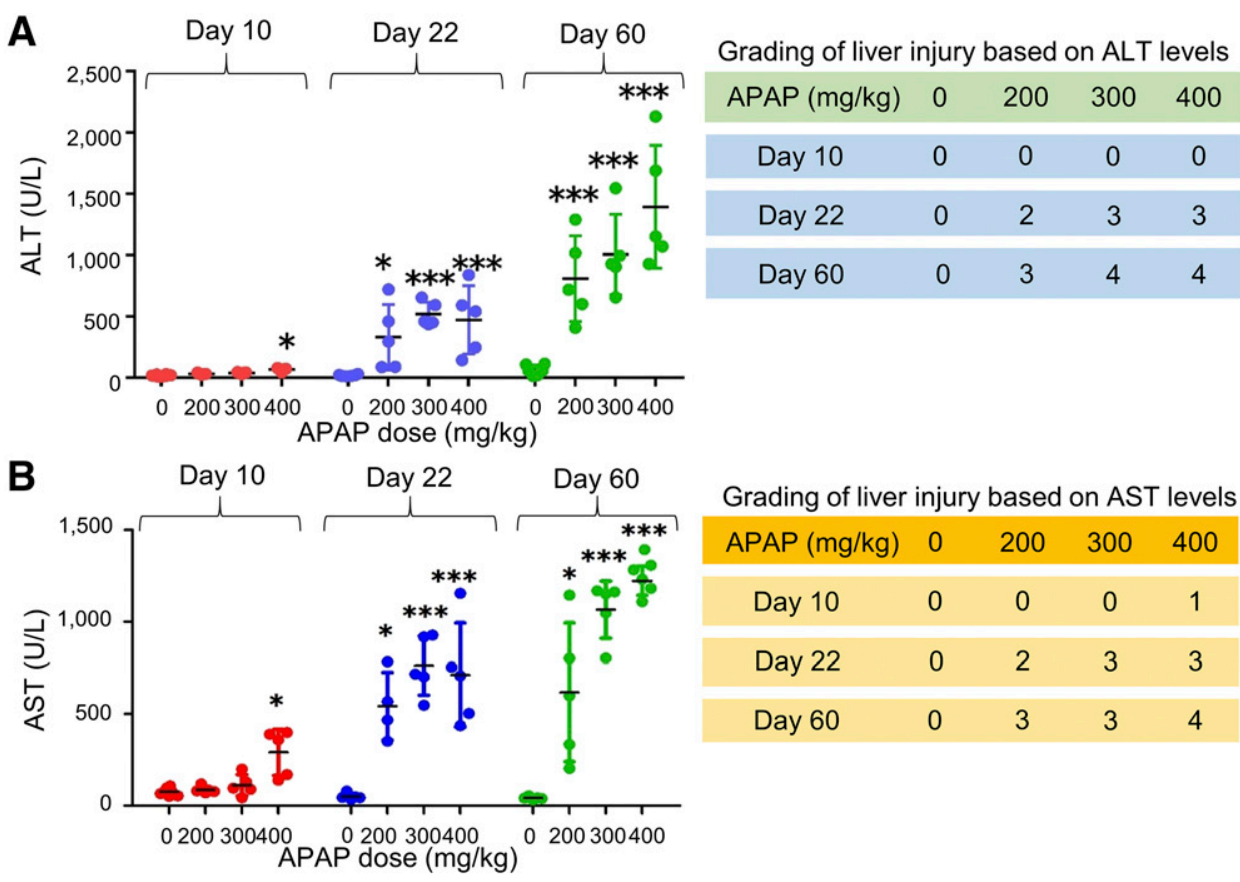

\begin{tabular}{|c|c|c|c|c|}
\hline APAP $(\mathrm{mg} / \mathrm{kg})$ & 0 & 200 & 300 & 400 \\
\hline Day 10 & 0 & 0 & 0 & 1 \\
\hline Day 22 & 0 & 2 & 3 & 3 \\
\hline Day 60 & 0 & 3 & 3 & 4 \\
\hline
\end{tabular}

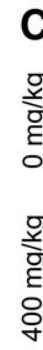

C Day 10

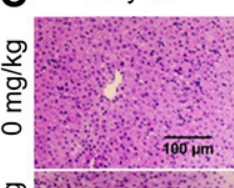

Day 22

Day 60

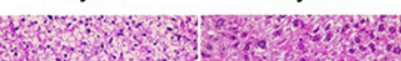

Grading of liver injury based on Ishak scores Age Day 10

$\begin{array}{llll}\text { APAP } 0 \mathrm{mg} / \mathrm{kg} & 0 & 0 & 0 \\ \text { APAP } 400 \mathrm{mg} / \mathrm{kg} & 0 & 2 & 5\end{array}$

Fig. 1. Impact of APAP treatment on liver injury in male mice at different ages. Male mice at different ages (postnatal day 10, 22, or 60) were treated with APAP at a series of doses $(0$, 200,300 , or $400 \mathrm{mg} / \mathrm{kg}$ ). Blood samples and liver tissues were collected at 24 hours after the treatment. (A) Left panel: plasma ALT activities; right panel: grades of liver injury defined based on ALT levels. (B) Left panel: plasma AST activities; right panel: grades of liver injury defined based on AST levels. (C) Left panel: representative images of liver sections stained with $\mathrm{H} \& \mathrm{E}$ from mice treated with $400 \mathrm{mg} / \mathrm{kg}$ APAP and age-matched controls $(0 \mathrm{mg} / \mathrm{kg})$; right panel: grades of liver injury defined based on Ishak scores. Scale bar, 100 $\mu \mathrm{m}$. Data are shown as means \pm S.D. $(n=$ 4-6) and analyzed by one-way ANOVA with Dunnett's post hoc test. $* P<0.05 ; * * * P<$ 0.001 vs. age-matched controls. by APAP in the mice at days 22 and 60, it was still much higher than in the control mice at day 10 (Fig. 4B).

The enzyme activity of CYP2C29 was determined by an UPLCQTOFMS method using the formation rates of demethyl-RSG in liver S9 samples from the control and APAP-treated mice at $400 \mathrm{mg} / \mathrm{kg}(n=$ 4). Consistent with the basal expression of CYP2C29 at mRNA and protein levels, the enzyme activity of CYP2C29 was increased in the mice at day 22 compared with the mice at day 10 (Fig. 4C). After APAP treatment, the mice at day 60 had a lower enzyme activity of CYP2C29 than the age-matched controls (Fig. 4C).

Overall, APAP treatment resulted in decreased expression of CYP2C29 at levels of mRNA, protein, and enzyme activity at each age.

Effects of AILI on Expression and Activity of CYP2E1 in Mouse Liver at Different Ages. The expression of CYP2E1 at the levels of mRNA, protein, and enzyme activity was also measured in this study. For the basal mRNA expression of CYP2E1, slightly higher expression was found in the mice at day 22 and a dramatically elevated level was seen in the mice at day 60 with 4-fold higher than the mice at day 10 (Fig. 5A). Generally, APAP treatment decreased the mRNA expression of CYP2E1 at all ages. The mice at day 10 treated with $400 \mathrm{mg} / \mathrm{kg}$ APAP had a significantly lower mRNA expression of CYP2E1, whereas only lower doses of APAP treatment (200 and $300 \mathrm{mg} / \mathrm{kg}$ ) decreased the mRNA expression of CYP2E1 in the mice at day 60 (Fig. 5A). However, APAP treatment at each dose repressed the mRNA expression of CYP2E1 in the mice at day 22 compared with the age-matched controls (Fig. 5A).

The relative protein levels of CYP2E1 were measured in control $(0 \mathrm{mg} / \mathrm{kg})$ and APAP-treated $(400 \mathrm{mg} / \mathrm{kg})$ mice at each age $(n=3$ to 4$)$.
Similar to the basal mRNA expression of CYP2E1, the protein levels were also higher in the mice at days 22 and 60 than day 10 (Fig. 5B). Consistent with the decreased mRNA expression of CYP2E1 by APAP treatment, reduced protein expression of CYP2E1 was also observed in the mice at day 22 (Fig. 5B). Moreover, significantly lower protein expression of CYP2E1 was found in the mice at day 60 treated with APAP compared with the age-matched controls (Fig. 5B).

The enzyme activity of CYP2E1 was determined by an UPLCQTOFMS method using the formation rates of 6-OH-CHZ in liver S9 samples from the control and APAP-treated mice at $400 \mathrm{mg} / \mathrm{kg}(n=4)$. Consistent with the basal mRNA and protein expression of CYP2E1, the enzyme activity was also higher in the mice at days 22 and 60 compared with the mice at day 10 (Fig. 5C). A trend of decrease of enzyme activity of CYP2E1 was found in the mice at days 22 and 60 treated with $400 \mathrm{mg} / \mathrm{kg}$ APAP compared with age-matched controls (Fig. 5C).

Overall, APAP treatment reduced the expression of CYP2E1 at the levels of mRNA, protein, and enzyme activity at each age.

Effects of AILI on Expression and Activity of CYP3A11 in Mouse Liver at Different Ages. The basal expression of CYP3A11 at mRNA level was higher in the older mice at days 22 and 60 with a 2- and 8 -fold increase, respectively, than the mice at day 10 (Fig. 6A). This is reflective to a normal ontogenic expression pattern for CYP3A11 during postnatal liver maturation. In general, APAP treatment resulted in decreased mRNA expression of CYP3A11, which was correlated with the severity degree of tissue injury. In the mice at day 10, CYP3A11 mRNA expression was decreased only in the $400 \mathrm{mg} / \mathrm{kg}$ APAP-treated mice (Fig. 6A). In the mice at day 22, CYP3A11 mRNA levels were 
A

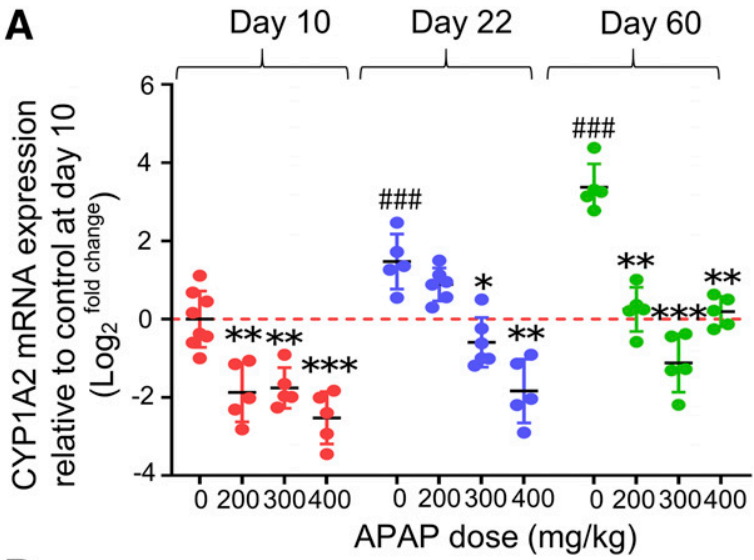

B
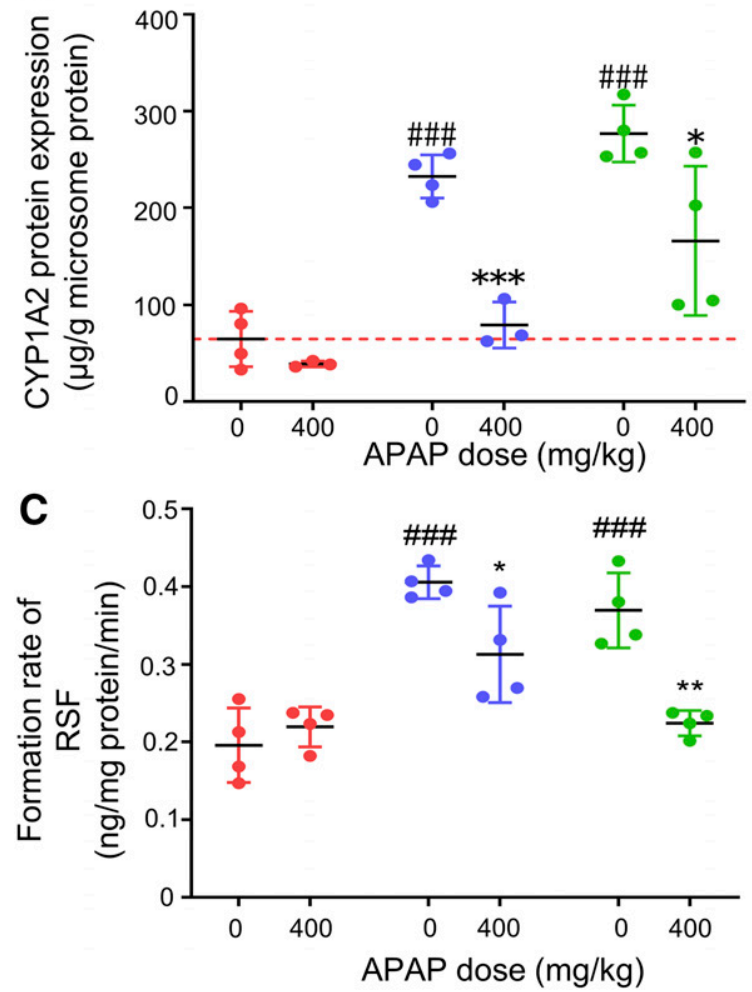

Fig. 2. Effects of APAP treatment on the expression of CYP1A2. Male mice at different ages (postnatal day 10, 22, or 60) were treated with APAP at a series of doses $(0,200,300$, or $400 \mathrm{mg} / \mathrm{kg})$. Liver tissues were collected at 24 hours after the treatment. (A) Hepatic mRNA expression of CYP1A2 $(n=4-6)$. The fold changes of relative mRNA expression compared with the control mice at day 10 were calculated using the $2^{-\Delta \Delta t}$ method after normalization with GAPDH. (B) The protein expression of CYP1A2 in liver microsomes from the mice treated with 0 or $400 \mathrm{mg} / \mathrm{kg}$ APAP ( $n=3$ to 4 ). The relative protein expression of CYP1A2 was determined by LC-MS/MS with normalization to external added BSA. (C) Enzyme activity of CYP1A2 in liver S9 fractions of mice treated with 0 or $400 \mathrm{mg} / \mathrm{kg}$ APAP $(n=4)$. Formation rates of 7-ethoxy-RSF to RSF were determined by UPLCQTOFMS. Data are presented as means \pm S.D. Statistical significance was determined by one-way ANOVA with Dunnett's post hoc test. $* P<0.05$; $* * P<$ $0.01 ; * * * P<0.001$ vs. age-matched controls; ${ }^{\# \#} P<0.001$ vs. $0 \mathrm{mg} / \mathrm{kg}$ APAP treatment at day 10 .

decreased in all APAP-treated mice compared with the controls, but by less than 2-fold. In the mice at day 60, CYP3A11 mRNA decreased more than 2-fold in all APAP-treated mice compared with the controls, which is correlated to the AILI severity.

The relative protein levels of CYP3A11 were measured in control $(0 \mathrm{mg} / \mathrm{kg})$ and APAP-treated $(400 \mathrm{mg} / \mathrm{kg})$ mice at each age $(n=3$ to 4$)$.

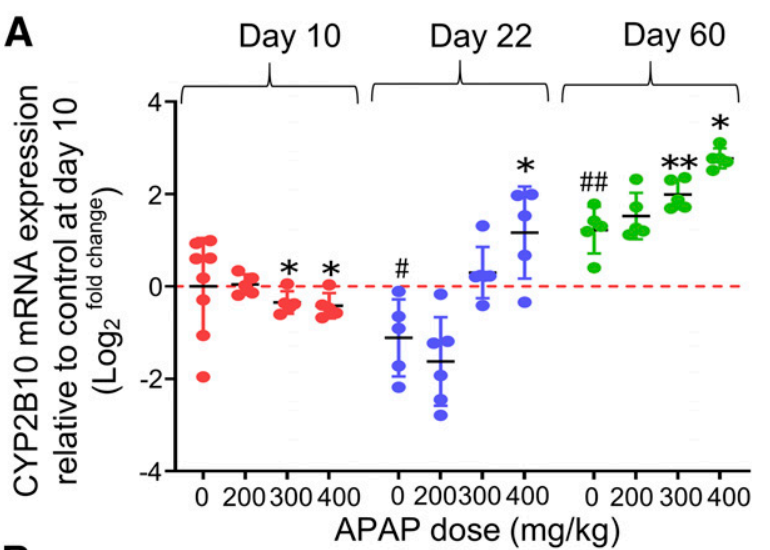

B
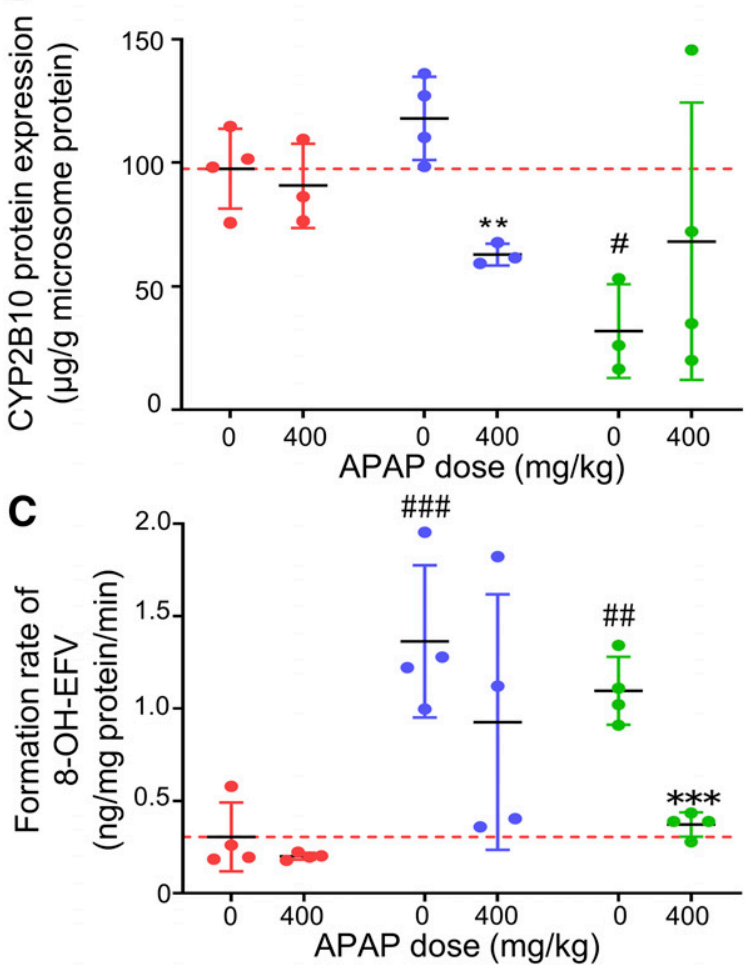

Fig. 3. Effects of APAP treatment on the expression and activity of CYP2B10. Male mice at different ages (postnatal day 10, 22, or 60) were treated with APAP at a series of doses $(0,200,300$, or $400 \mathrm{mg} / \mathrm{kg})$. Liver tissues were collected at 24 hours after the treatment. (A) Hepatic mRNA expression of CYP2B10 $(n=4-6)$. The fold changes of relative mRNA expression compared with the control mice at day 10 were calculated using the $2^{-\Delta \Delta t}$ method after normalization with GAPDH. (B) The protein expression of CYP2B10 in liver microsomes from the mice treated with 0 or $400 \mathrm{mg} / \mathrm{kg}$ APAP ( $n=3$ to 4 ). The relative protein expression of CYP2B10 was determined by LC-MS/MS with normalization to external added BSA. (C) Enzyme activity of CYP2B10 in liver S9 fractions of mice treated with 0 or $400 \mathrm{mg} / \mathrm{kg}$ APAP $(n=4)$. Formation rates of $8-\mathrm{OH}-\mathrm{EFV}$ were determined by UPLC-QTOFMS. Data are presented as means \pm S.D. Statistical significance was determined by one-way ANOVA with Dunnett's post hoc test. $* P<0.05$; $* * P<$ $0.01 ; * * * P<0.001$ vs. age-matched controls; ${ }^{\#} P<0.05 ;{ }^{\# \#} P<0.01 ;{ }^{\# \# \# P<0.001}$ vs. $0 \mathrm{mg} / \mathrm{kg}$ APAP treatment at day 10.

Consistent with higher basal mRNA expression of CYP3A11 in the mice at days 22 and 60, the protein expression of CYP3A11 was also higher in the mice at days 22 and 60 compared with day 10 (Fig. 6B). Similar to the effect of APAP on the mRNA expression of CYP3A11, the APAP treatment also resulted in a significantly decreased protein expression of CYP3A11 in the mice at days 22 and 60. Especially, the protein level of CYP3A11 in the mice at day 60 with APAP treatment was decreased to a similar level as the controls at day 10 (Fig. 6B). 
A

Day 10 Day 22 Day 60

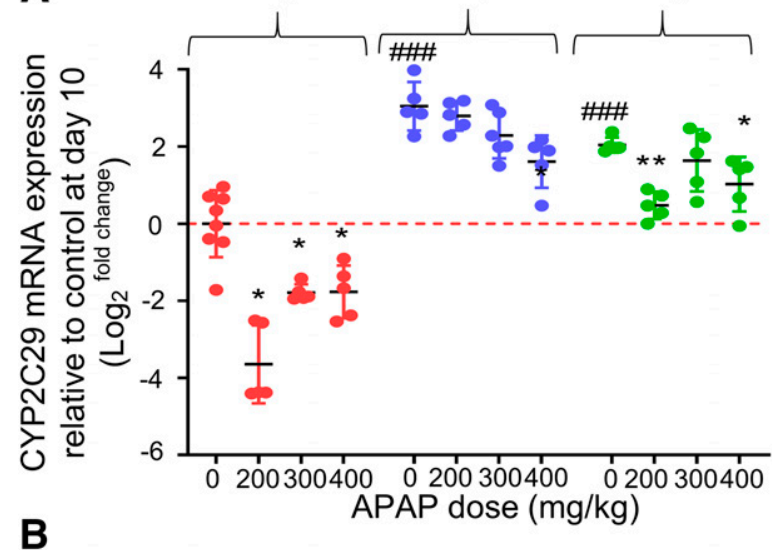

B

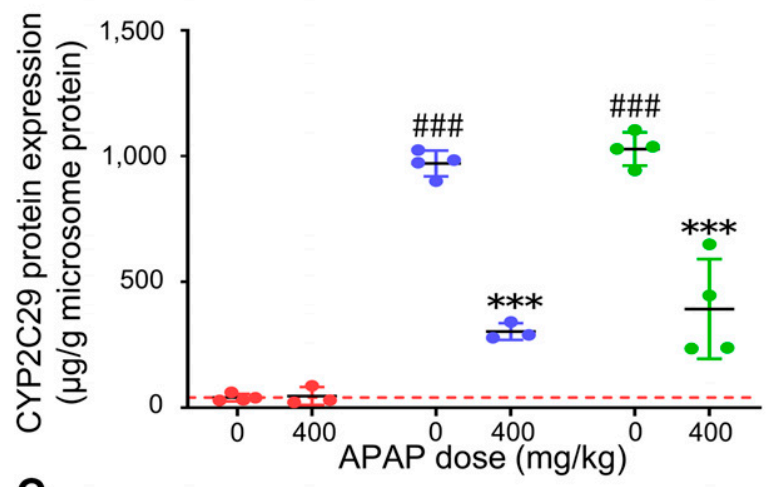

C

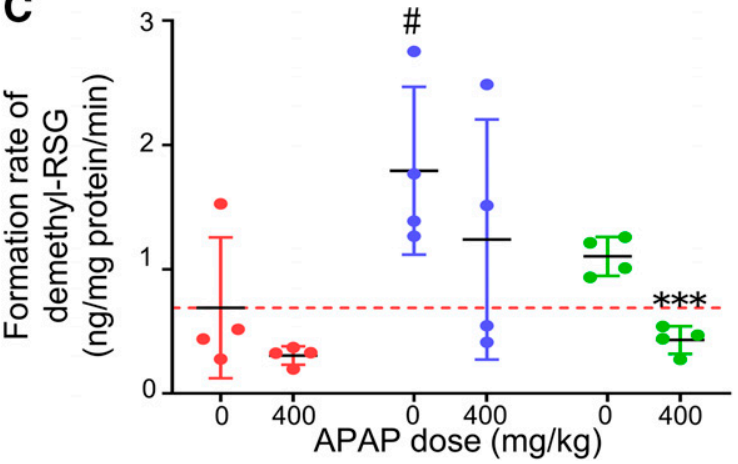

Fig. 4. Effects of APAP treatment on the expression and activity of CYP2C29. Male mice at different ages (postnatal day 10,22, or 60) were treated with APAP at a series of doses $(0,200,300$, or $400 \mathrm{mg} / \mathrm{kg})$. Liver tissues were collected at 24 hours after the treatment. (A) Hepatic mRNA expression of CYP2C29 $(n=4-6)$. The fold changes of relative mRNA expression compared with the control mice at day 10 were calculated using the $2^{-\Delta \Delta t}$ method after normalization with GAPDH. (B) The protein expression of CYP2C29 in liver microsomes from the mice treated with 0 or $400 \mathrm{mg} / \mathrm{kg}$ APAP ( $n=3$ to 4 ). The relative protein expression of CYP2C29 was determined by LC-MS/ MS with normalization to external added BSA. (C) Enzyme activity of CYP2C29 in liver S9 fractions of mice treated with 0 or $400 \mathrm{mg} / \mathrm{kg}$ APAP $(n=4)$. Formation rates of demethyl-RSG were determined by UPLC-QTOFMS. Data are presented as means \pm S.D. Statistical significance was determined by one-way ANOVA with Dunnett's post hoc test. ${ }^{*} P<0.05 ;{ }^{*} P<<0.01 ;{ }^{*} * * P<0.001$ vs. age-matched controls; ${ }^{*} P<$

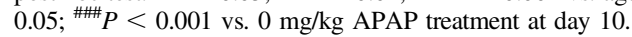

The enzyme activity of CYP3A11 was determined by an UPLCQTOFMS method using the formation rates of 1-OH-MDZ in liver S9 samples from the control and APAP-treated mice at $400 \mathrm{mg} / \mathrm{kg}(n=4)$. Consistent with the mRNA and protein expression of CYP3A11, the basal enzyme activity of CYP3A11 was increased with age and decreased by APAP treatment (Fig. 6C).

Overall, APAP treatment reduced the expression of CYP3A11 at the levels of mRNA, protein, and enzyme activity at each age in a dose-dependent manner.

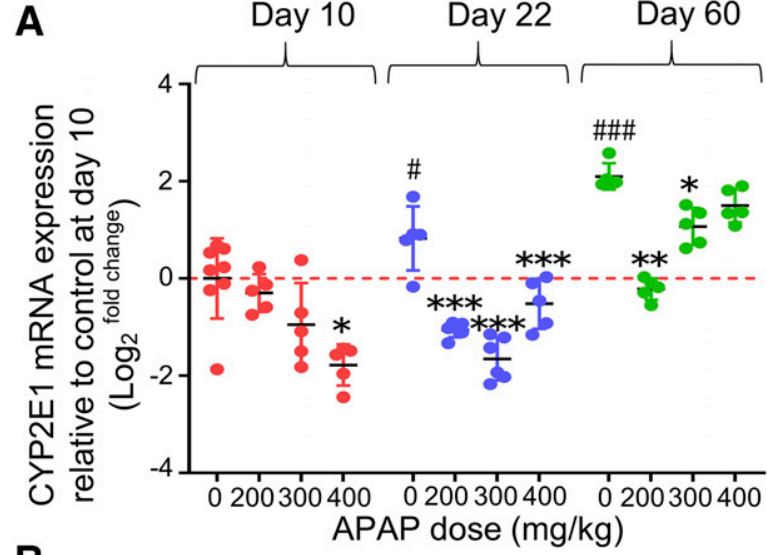

B
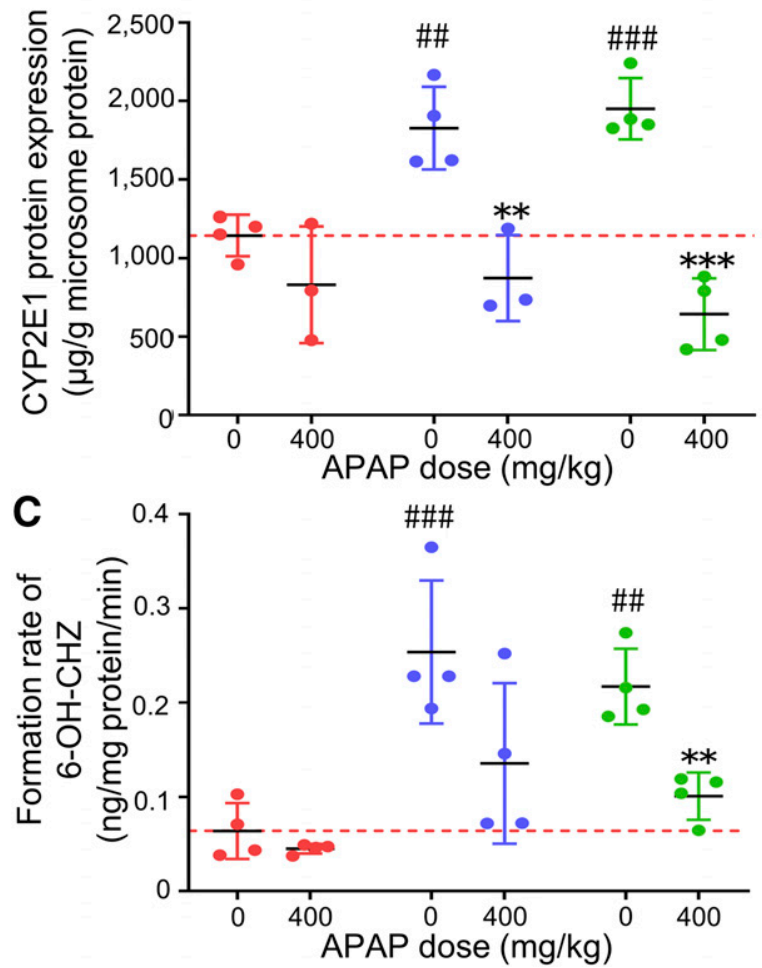

Fig. 5. Effects of APAP treatment on the expression and activity of CYP2E1. Male mice at different ages (postnatal day 10, 22, or 60) were treated with APAP at a series of doses $(0,200,300$, or $400 \mathrm{mg} / \mathrm{kg})$. Liver tissues were collected at 24 hours after the treatment. (A) Hepatic mRNA expression of CYP2E1 $(n=4-6)$. The fold changes of relative mRNA expression compared with the control mice at day 10 were calculated using the $2^{-\Delta \Delta t}$ method after normalization with GAPDH. (B) The protein expression of CYP2E1 in liver microsomes from the mice treated with 0 or $400 \mathrm{mg} / \mathrm{kg}$ APAP ( $n=3$ to 4 ). The relative protein expression of CYP2E1 was determined by LC-MS/MS with normalization to external added BSA. (C) Enzyme activity of CYP2E1 in liver S9 fractions of mice treated with 0 or $400 \mathrm{mg} / \mathrm{kg}$ APAP $(n=4)$. Formation rates of 6-OH-CHZ were determined by UPLC-QTOFMS. Data are presented as means \pm S.D. Statistical significance was determined by one-way ANOVA with Dunnett's post hoc test. $* P<0.05 ; * * P<0.01 ; * * * P<0.001$ vs. age-matched controls; ${ }^{\#} P<0.05 ;{ }^{\# \#} P<0.01 ;{ }^{\# \# \#} P<0.001$ vs. $0 \mathrm{mg} / \mathrm{kg}$ APAP treatment at day 10 .

Impact on APAP Treatment in Mice by Sex. We then investigated whether sex affected the severity of AILI and the consequence of AILI on the expression of P450s. In this study, both male and female mice at day 60 were used, and the mRNA expression of CYP3A11 was determined.

As seen in Fig. 7, APAP treatment significantly increased the levels of ALT and AST in both sexes, indicating that AILI occurred. After 

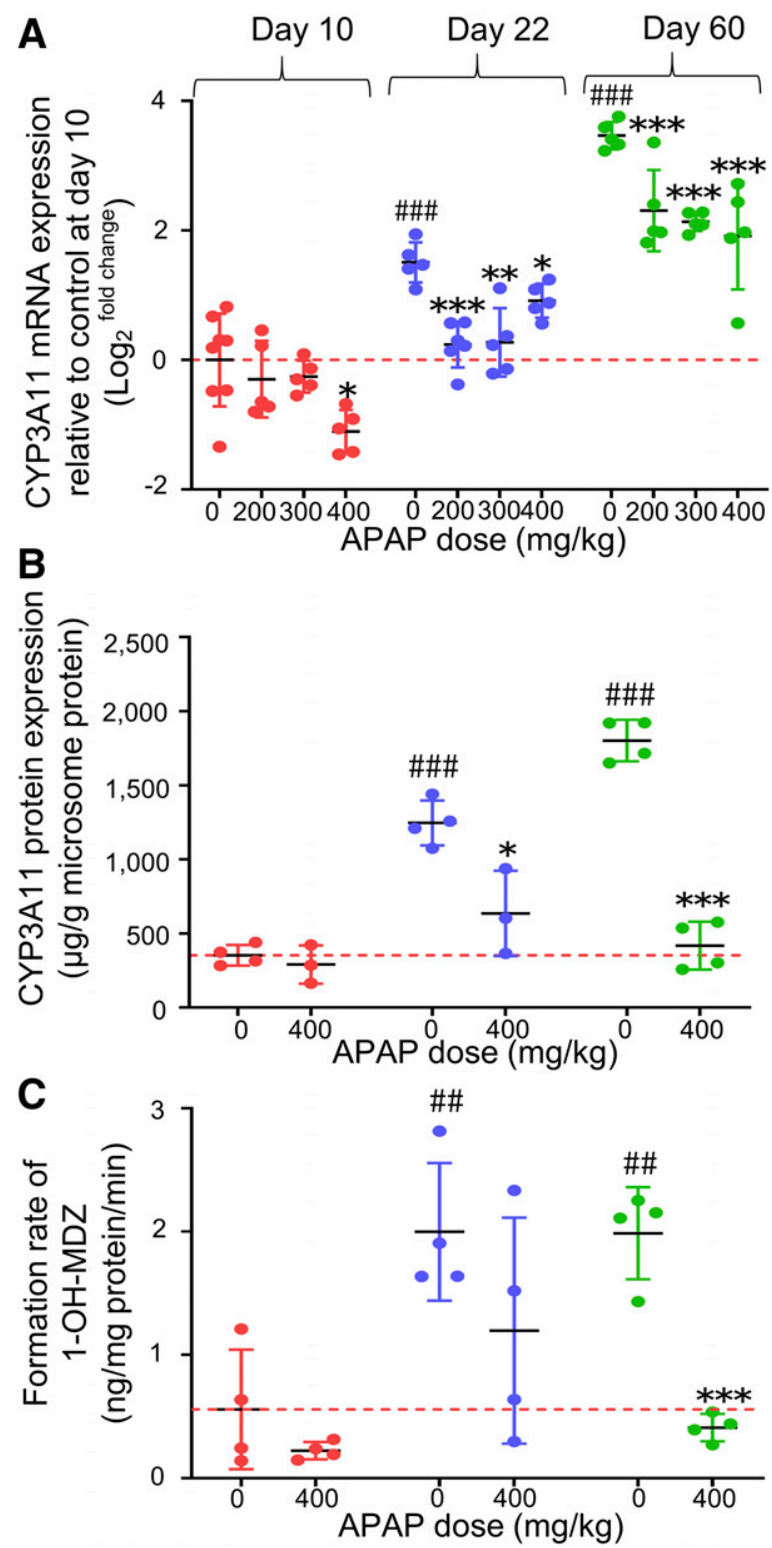

Fig. 6. Effects of APAP treatment on the expression and activity of CYP3A11. Male mice at different ages (postnatal day 10,22, or 60) were treated with APAP at a series of doses $(0,200,300$, or $400 \mathrm{mg} / \mathrm{kg})$. Liver tissues were collected at 24 hours after the treatment. (A) Hepatic mRNA expression of CYP3A11 $(n=4-6)$. The fold changes of relative mRNA expression compared with the control mice at day 10 were calculated using the $2^{-\Delta \Delta t}$ method after normalization with GAPDH. (B) The protein expression of CYP3A11 in liver microsomes from the mice treated with 0 or $400 \mathrm{mg} / \mathrm{kg}$ APAP ( $n=3$ to 4 ). The relative protein expression of CYP3A11 was determined by LC-MS/MS with normalization to external added BSA. (C) Enzyme activity of CYP3A11 in liver S9 fractions of mice treated with 0 or $400 \mathrm{mg} / \mathrm{kg}$ APAP $(n=4)$. Formation rates of 1-OH-MDZ were determined by UPLC-QTOFMS. Data are presented as means \pm S.D. $* P<0.05$; $* * * P<0.001$ vs. age-matched controls; ${ }^{\# \#} P<0.01 ;{ }^{\# \# \#} P<0.001$ vs. $0 \mathrm{mg} / \mathrm{kg}$ APAP treatment at day 10 .

treatment with the same doses of APAP, alteration magnitudes of ALT and AST changes were greater in the males than females. Consistent with grading of liver injury based on ALT or AST levels, H\&E staining results showed more severe injury induced by $400 \mathrm{mg} / \mathrm{kg}$ APAP in male mice than in female mice (Fig. 7C).

The expression of mRNA level of CYP3A11 was compared to their sex-match controls (Fig. 7D). Accompanied with AILI, the hepatic mRNA expression of CYP3A11 was decreased in both males and females. The same doses of APAP treatment resulted in lower mRNA expression in males than in females. After the same doses of APAP treatment, the mRNA expression of CYP3A11 in the male mice, which had more severe liver injury, was decreased even more than that in female mice.

Overall, APAP treatment led to severe liver injury and lower mRNA expression of CYP3A11 in male more than in female mice.

\section{Discussion}

The current study confirmed the role of ontogeny of P450s in the severity of AILI at different ages and investigated the age-dependent differences on the consequences of AILI on the hepatic expression and activities of P450s in mice. In this study, the mice at day 10, which had lower basal expression levels of P450s, were observed to be less susceptible to AILI in comparison with the mice at days 22 and 60 . CYP1A2, 2B10, 2C29, 2E1, and 3A11 were selected because they are the major $\mathrm{P} 450$ s in mice correlated to the human $\mathrm{P} 450$ s responsible for drug metabolism. Decreased expression levels of P450s (except CYP2B10) by AILI were also observed in mice at different ages.

Susceptibility to APAP toxicity has been studied in various species (McGill et al., 2012; Jaeschke et al., 2014). Mice are more vulnerable to AILI compared with rats (McGill et al., 2012). Importantly, mice are identified as a more clinically relevant model of AILI than rats because of similar mechanisms of toxicity, including severe mitochondrial dysfunction accompanied by high oxidative stress, in mice and humans (Jaeschke et al., 2014). In addition, cell models are not suitable to study age-related effects. Thus, it is reasonable to use the mouse model in the present study. In this study, mice at days 10, 22, and 60 were selected to mimic the stages of infant, child, and adult in humans, respectively, based on our previous studies related to the ontogenic expression of P450s (Hart et al., 2009; Peng et al., 2012).

Intensity of liver injury is dose-dependent (Jaeschke, 2015). Generally, the doses of 200-500 mg/kg APAP are used to treat adult mice to cause AILI (Harrill et al., 2009; Imaeda et al., 2009). In this study, three doses of APAP $(200,300$, and $400 \mathrm{mg} / \mathrm{kg}$ ) were selected based on previous studies. The results of ALT and AST levels in plasma as well as H\&E staining confirmed an injury of liver in adult mice as expected. Mice at younger ages were reported to be more resistant to AILI (Adamson et al., 1991). In the present study, the resistance to AILI in the mice at the infant age was further confirmed. For details, the treatment with APAP at 200,300, and $400 \mathrm{mg} / \mathrm{kg}$ did not induce liver injury in the mice at day 10, whereas the same doses of APAP caused mild to severe liver injury in the mice at day 22 and severe to life threatening liver injury in the mice at day 60. Consistent with literature, lower expression levels of selected P450s were observed in the liver of mice at younger ages in the current study. The resistance to AILI in the mice at day 10 is partly due to the lower activities of CYP1A2, 2E1, and 3A11, which are responsible for metabolism of APAP to a toxic metabolite NAPQI. The differences in the capability of metabolism of APAP in the mice between days 10 and 60 have been confirmed by a lower rate of in vitro metabolism of APAP by microsomal proteins from the mice at day 10 compared with the mice at day 60 (Supplemental Fig. 1).

Previous studies have reported altered expression of P450s by APAP treatment at subtoxic doses and overdoses (Gill et al., 2017; Jeong et al., 2019; Ohtsuki et al., 2019). However, contradictory results were observed in these studies. The influence of APAP treatment at infant age on the expression of P450s is also unclear. In HepaRG cells, a high concentration of APAP was found to down-regulate the mRNA expression of CYP1A2, 2E1, and 3A4 (Gill et al., 2017), whereas, in in vivo studies, treatment of mice with $300 \mathrm{mg} / \mathrm{kg}$ APAP increased the expression of CYP1A2 (Chowdhary et al., 2017). In the present study, 

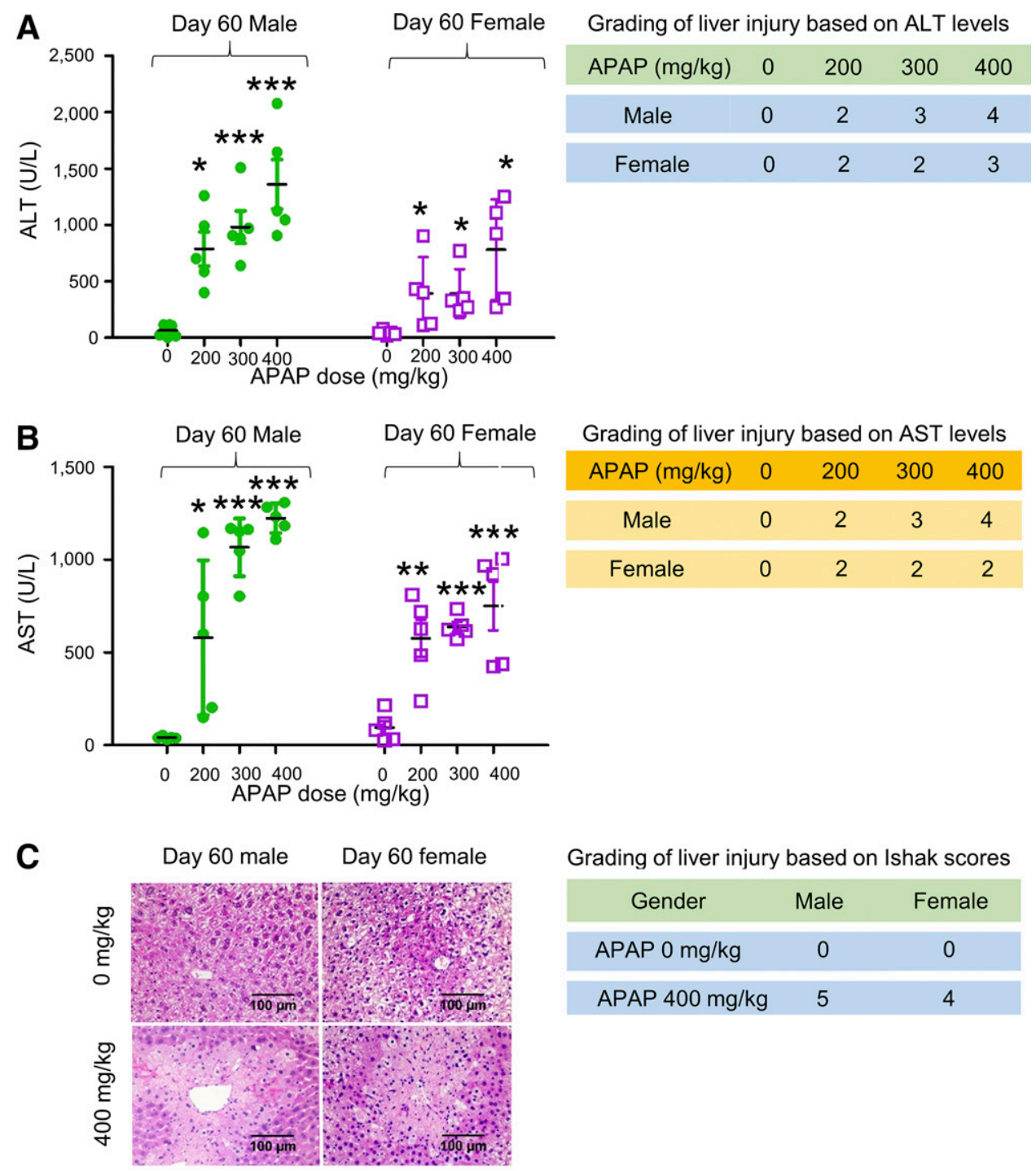

\begin{tabular}{|ccc|}
\hline \multicolumn{3}{c}{ Grading of liver injury based on lshak scores } \\
\hline Gender & Male & Female \\
\hline APAP $0 \mathrm{mg} / \mathrm{kg}$ & 0 & 0 \\
\hline APAP $400 \mathrm{mg} / \mathrm{kg}$ & 5 & 4 \\
\hline
\end{tabular}

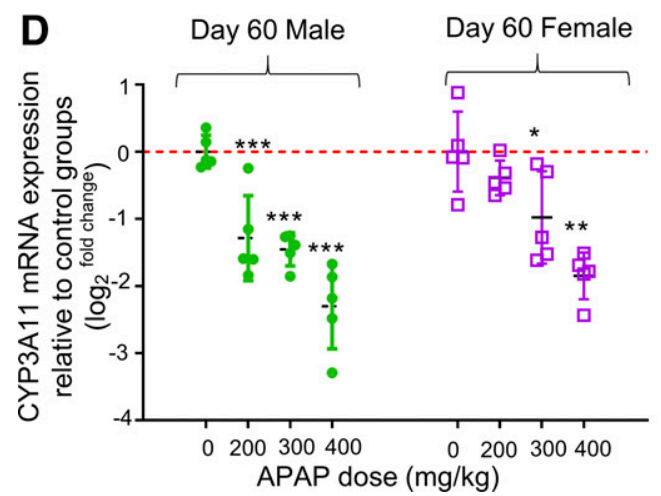

lower expression levels of CYP1A2, 2C29, 2E1, and 3A11 were seen in the mice with AILI at days 22 and 60, which is consistent with the previous in vitro study. A subtoxic dose of APAP was found to elevate the expression of hepatic CYP2E1 and CYP3A proteins in adult rats (Kim et al., 2007). However, in the current study, APAP-treated mice at day 10 had decreased expression of all selected P450s although no liver injury was evident. This may be due to different species as well as different ages of rodents used. In the previous study, adult rats were used to investigate the impact of subtoxic doses of APAP, whereas infant mice groups were selected as no liver injury was induced by APAP. Importantly, the present results were consistent with the study in HepaRG cells, which is a good in vitro model to mimic the APAP treatment in humans (McGill et al., 2011; Xie et al., 2015).

In addition, differences in susceptibility to APAP and its consequence on P450 expression were investigated in different sexes in the current study. APAP treatment at three doses elevated the ALT and AST levels
Fig. 7. Sex differential impacts of APAP mouse liver. Both male and female different doses of APAP $(0,200,300$, or $400 \mathrm{mg} / \mathrm{kg}$ ). Blood and liver tissues were collected at 24 hours after the treatment. (A) (B. pasma ALT activities; right panel: levels. (B) Left panel: plasma AST activities; right panel: grades of liver injury defined based on AST levels. (C) Upper panel: representative images of liver sections stained with $\mathrm{H} \& \mathrm{E}$ from mice treated with $400 \mathrm{mg} / \mathrm{kg}$ APAP and sexmatched controls $(0 \mathrm{mg} / \mathrm{kg})$; lower panel: of liver injury defined based on Ishak changes of relative CYP3A11 mRNA expression compared with the sex-matched controls calculated using the $2^{-\Delta \Delta t}$ method after normalization with GAPDH. Data are presented as 0.001 vs. sex-matched controls. 
in both male and female mice (Fig. 7, A and B). Liver injury was also confirmed by H\&E staining, and severe injury was seen in all the APAPtreated mice (Fig. 7C). Compared with male mice, lower levels of ALT and AST as well as relatively less severe injury were found in female mice treated with the same doses of APAP, indicating that male mice are more vulnerable to AILI than female mice. This finding is consistent with previous studies (Du et al., 2014).

Although the mechanisms of AILI have been well established, the underlying mechanism of altered expression of P450s by APAP treatment has not been elucidated. Events involved in the regulation of $\mathrm{P} 450$ s may play roles in the altered expression of P450s by APAP. For instance, necrosis causing cell mass loss may be responsible for the decrease of P450 expression. In AILI, necrosis mainly happened around a central vein area of the liver, where P450s are primarily expressed (Kietzmann, 2017; Kitaoka et al., 2018). Further immunostaining experiment may be required to test the zonation changes of $\mathrm{P} 450$ s with APAP treatment. In addition, endoplasmic reticulum stress (Nagy et al., 2007), which activates gene expression in AILI, represses the expression of CYP3A4 in HepG2 cells (Vachirayonsti et al., 2015). Treatment with interleukin-6 has a similar effect, indicating the potential relationship between inflammation and P450 expression. Further knock-in and knock-down experiments may need to investigate the signaling pathways involved. Recent research demonstrated that microRNAs (miRNAs) may contribute to the altered expression of P450s in AILI. Elevated expression of miRNAs, e.g., miR-122-5p and miR-378a-5p, in AILI contributed to altered expression of CYP1A2, 2E1, and 3A4 in HepRG2 cells (Gill et al., 2017). Knockdown of long noncoding RNAs HNF1a-AS1 and HNF4a-AS1 alters susceptibility to APAP-induced cytotoxicity in HepaRG cells (Chen et al., 2020). The roles of noncoding RNAs (including miRNAs and long noncoding RNAs) in the alterations of P450 expression by APAP should be investigated in future studies. In addition to APAP, many other drugs can result in DILI by various mechanisms. Impact on P450 expression by DILI should be studied with more drugs than APAP.

Currently, there is no discussion in the clinical setting on how to handle coadministered drugs in patients who experience AILI. Very likely, the current practice is to stop all drugs when AILI happens. However, such a decision is not based on sound science but instead on a logical concern by clinicians that patients with liver injury may have an altered capacity to metabolize drugs. Many patients with AILI may have chronic conditions, such as diabetes, hypertension, hyperlipidemia, and depression, under control by multiple medications. P450s play an important role in metabolism of drugs to treat many chronic diseases. Management of these diseases requires a long period of treatment with medications, even the lifetime. Understanding how expression and activities of the P450s are altered under an AILI condition is clinically critical. The data in this manuscript may stimulate more studies on how to make evidence-based decisions on dosage of drugs in management of various conditions in patients who experience AILI.

In conclusion, the present study indicates that adult mice are more vulnerable to AILI compared with infant mice, which may be due to the higher expression levels of P450s at the adult age. It is also demonstrated that AILI results in reduced expression of P450s (except CYP2B10) in mice, which may influence the metabolism and toxicity of drugs that are substrates for these enzymes when coadministered with APAP. Moreover, male mice are more susceptible to AILI than female mice. Further studies are needed to explore the underlying mechanisms of reduction of P450s by AILI.

\section{Authorship Contributions}

Participated in research design: Bao, Wang, Zhang, J. Zhu, Ma, Manautou, Zhong.
Conducted experiments: Bao, Wang, Shao, Xiao, Shi, J. Zhu.

Performed data analysis: Bao, Wang, Zhong.

Wrote or contributed to the writing of the manuscript: Bao, Wang, Shao, Zhang, HJ. Zhu, Ma, Manautou, Zhong.

\section{References}

Adamson GM, Papadimitriou JM, and Harman AW(1991) Postnatal mice have low susceptibility to paracetamol toxicity. Pediatr Res 29:496-499.

Bell LN and Chalasani N(2009) Epidemiology of idiosyncratic drug-induced liver injury. Semin Liver Dis 29:337-347.

Brewer CT and Chen T(2017) Hepatotoxicity of herbal supplements mediated by modulation of cytochrome P450. Int J Mol Sci 18:E2353.

Bunchorntavakul C and Reddy KR(2013) Acetaminophen-related hepatotoxicity. Clin Liver Dis 17:587-607, viii.

Chen L, Wang P, Manautou JEE, and Zhong XB (2020) Knockdown of LncRNAs HNF1 $\alpha$-AS1 and $\mathrm{HNF} 4 \alpha$-AS1 alters susceptibility of acetaminophen-induced cytotoxicity in HepaRG cells Mol Pharmacol DOI: 10.1124/mol.119.118778 [published ahead of print].

Chowdhary V, Teng KY, Thakral S, Zhang B, Lin CH, Wani N, Bruschweiler-Li L, Zhang X, James L, Yang D, et al.(2017) miRNA-122 protects mice and human hepatocytes from acetaminophen toxicity by regulating cytochrome P450 family 1 subfamily A member 2 and family 2 subfamily E member 1 expression. Am J Pathol 187:2758-2774.

Corsini A and Bortolini M(2013) Drug-induced liver injury: the role of drug metabolism and transport. J Clin Pharmacol 53:463-474.

Dahlin DC, Miwa GT, Lu AY, and Nelson SD(1984) N-acetyl-p-benzoquinone imine: a cytochrome P-450-mediated oxidation product of acetaminophen. Proc Natl Acad Sci USA 81:1327-1331.

Dai G, He L, Chou N, and Wan Y-JY(2006) Acetaminophen metabolism does not contribute to gender difference in its hepatotoxicity in mouse. Toxicol Sci 92:33-41.

Du K, Williams CD, McGill MR, and Jaeschke H(2014) Lower susceptibility of female mice to acetaminophen hepatotoxicity: role of mitochondrial glutathione, oxidant stress and c-jun N-terminal kinase. Toxicol Appl Pharmacol 281:58-66.

Fernández I, Peña A, Del Teso N, Pérez V, and Rodríguez-Cuesta J(2010) Clinical biochemistry parameters in C57BL/6J mice after blood collection from the submandibular vein and retroorbital plexus. J Am Assoc Lab Anim Sci 49:202-206.

Fontana RJ(2008) Acute liver failure including acetaminophen overdose. Med Clin North Am 92: 761-794, viii.

Gavito AL, Cabello R, Suarez J, Serrano A, Pavón FJ, Vida M, Romero M, Pardo V, Bautista D, Arrabal S, et al.(2016) Single administration of recombinant IL-6 restores the gene expression of lipogenic enzymes in liver of fasting IL-6-deficient mice. Br J Pharmacol 173:1070-1084.

Gill P, Bhattacharyya S, McCullough S, Letzig L, Mishra PJ, Luo C, Dweep H, and James L(2017) MicroRNA regulation of CYP 1A2, CYP3A4 and CYP2E1 expression in acetaminophen toxicity. Sci Rep 7:12331.

Goodman ZD(2007) Grading and staging systems for inflammation and fibrosis in chronic liver diseases. J Hepatol 47:598-607.

Guo GL, Moffit JS, Nicol CJ, Ward JM, Aleksunes LA, Slitt AL, Kliewer SA, Manautou JE, and Gonzalez FJ(2004) Enhanced acetaminophen toxicity by activation of the pregnane X receptor. Toxicol Sci 82:374-380.

Harrill AH, Watkins PB, Su S, Ross PK, Harbourt DE, Stylianou IM, Boorman GA, Russo MW, Sackler RS, Harris SC, et al.(2009) Mouse population-guided resequencing reveals that variants in CD44 contribute to acetaminophen-induced liver injury in humans. Genome Res 19: $1507-1515$

Hart SN, Cui Y, Klaassen CD, and Zhong XB(2009) Three patterns of cytochrome P450 gene expression during liver maturation in mice. Drug Metab Dispos 37:116-121.

Hassan HM, Yousef BA, Guo H, Xiaoxin L, Zhang L, and Jiang Z(2018) Investigating the CYP2E1 potential role in the mechanisms behind INH/LPS-induced hepatotoxicity. Front Pharmacol 9:198.

Hoofnagle JH, Serrano J, Knoben JE, and Navarro VJ(2013) LiverTox: a website on drug-induced liver injury. Hepatology 57:873-874.

Imaeda AB, Watanabe A, Sohail MA, Mahmood S, Mohamadnejad M, Sutterwala FS, Flavell RA, and Mehal WZ(2009) Acetaminophen-induced hepatotoxicity in mice is dependent on Tlr9 and the Nalp3 inflammasome. J Clin Invest 119:305-314.

Jaeschke H(2015) Acetaminophen: dose-dependent drug hepatotoxicity and acute liver failure in patients. Dig Dis 33:464-471.

Jaeschke H, Xie Y, and McGill MR(2014) Acetaminophen-induced liver injury: from animal models to humans. J Clin Transl Hepatol 2:153-161.

Jeong TB, Kim J-H, Kim SH, Lee S, Son SW, Lim Y, Cho J-Y, Hwang DY, Kim KS, Kwak J-H, et al.(2019) Comparison of toxic responses to acetaminophen challenge in ICR mice originating from different sources. Lab Anim Res 35:16.

Kietzmann T(2017) Metabolic zonation of the liver: the oxygen gradient revisited. Redox Biol 11: 622-630.

Kim SN, Seo JY, Jung DW, Lee MY, Jung YS, and Kim YC(2007) Induction of hepatic CYP2E1 by a subtoxic dose of acetaminophen in rats: increase in dichloromethane metabolism and carboxyhemoglobin elevation. Drug Metab Dispos 35:1754-1758.

Kitaoka S, Hatogai J, Ochiai W, and Sugiyama K(2018) Zonation of the drug-metabolizing enzyme cytochrome P450 3A in infant mice begins in pre-weaning period. J Toxicol Sci 43:223-227. Larrey D(2002) Epidemiology and individual susceptibility to adverse drug reactions affecting the liver. Semin Liver Dis 22:145-155.

Leise MD, Poterucha JJ, and Talwalkar JA(2014) Drug-induced liver injury. Mavo Clin Proc 89:95-106 Maddrey WC(2005) Drug-induced hepatotoxicity: 2005. J Clin Gastroenterol 39 (4 Suppl 2): S83-S89.

McGill MR, Williams CD, Xie Y, Ramachandran A, and Jaeschke H(2012) Acetaminopheninduced liver injury in rats and mice: comparison of protein adducts, mitochondrial dysfunction, and oxidative stress in the mechanism of toxicity. Toxicol Appl Pharmacol 264:387-394.

McGill MR, Yan HM, Ramachandran A, Murray GJ, Rollins DE, and Jaeschke H(2011) HepaRG cells: a human model to study mechanisms of acetaminophen hepatotoxicity. Hepatology 53:974-982.

Nagy G, Kardon T, Wunderlich L, Szarka A, Kiss A, Schaff Z, Bánhegyi G, and Mandl J(2007) Acetaminophen induces ER dependent signaling in mouse liver. Arch Biochem Biophys 459: 273-279. 
Ohtsuki Y, Sanoh S, Santoh M, Ejiri Y, Ohta S, and Kotake Y(2019) Inhibition of cytochrome P450 3A protein degradation and subsequent increase in enzymatic activity through p38 MAPK activation by acetaminophen and salicylate derivatives. Biochem Biophys Res Commun 509: 287-293.

Otto GP, Rathkolb B, Oestereicher MA, Lengger CJ, Moerth C, Micklich K, Fuchs H, GailusDurner V, Wolf E, and Hrabě de Angelis M(2016) Clinical chemistry reference intervals for C57BL 6J, C57BL/6N, and C3HeB/FeJ mice (Mus musculus). J Am Assoc Lab Anim Sci 55:375-386.

Pasanen M, Pellinen P, Stenbäck F, Juvonen RO, Raunio H, and Pelkonen O(1995) The role of CYP enzymes in cocaine-induced liver damage. Arch Toxicol 69:287-290.

Peng L, Yoo B, Gunewardena SS, Lu H, Klaassen CD, and Zhong XB(2012) RNA sequencing reveals dynamic changes of mRNA abundance of cytochromes P450 and their alternative transcripts during mouse liver development. Drug Metab Dispos 40:1198-1209.

Piekos SC, Chen L, Wang P, Shi J, Yaqoob S, Zhu HJ, Ma X, and Zhong XB(2018) Consequences of phenytoin exposure on hepatic cytochrome $\mathrm{P} 450$ expression during postnatal liver maturation in mice. Drug Metab Dispos 46:1241-1250.

Rudraiah S, Rohrer PR, Gurevich I, Goedken MJ, Rasmussen T, Hines RN, and Manautou $\mathrm{JE}(2014)$ Tolerance to acetaminophen hepatotoxicity in the mouse model of autoprotection is associated with induction of flavin-containing monooxygenase-3 (FMO3) in hepatocytes. Toxicol Sci 141:263-277.

Sgro C, Clinard F, Ouazir K, Chanay H, Allard C, Guilleminet C, Lenoir C, Lemoine A, and Hillon $\mathrm{P}(2002)$ Incidence of drug-induced hepatic injuries: a French population-based study. Hepatology 36:451-455.

Shen T, Liu Y, Shang J, Xie Q, Li J, Yan M, Xu J, Niu J, Liu J, Watkins PB, et al.(2019) Incidence and etiology of drug-induced liver injury in mainland China. Gastroenterology 156: 2230-2241.e11.
Tien YC, Liu K, Pope C, Wang P, Ma X, and Zhong XB(2015) Dose of phenobarbital and age of treatment at early life are two key factors for the persistent induction of cytochrome P450 enzymes in adult mouse liver. Drug Metab Dispos 43:1938-1945.

Vachirayonsti T, Ho KW, Yang D, and Yan B(2015) Suppression of the pregnane X receptor during endoplasmic reticulum stress is achieved by down-regulating hepatocyte nuclear factor$4 \alpha$ and up-regulating liver-enriched inhibitory protein. Toxicol Sci 144:382-392.

Vega M, Verma M, Beswick D, Bey S, Hossack J, Merriman N, Shah A, and Navarro V; Drug Induced Liver Injury Network (DILIN) (2017) The incidence of drug- and herbal and dietary supplement-induced liver injury: preliminary findings from gastroenterologist-based surveillance in the population of the state of Delaware. Drug Saf 40:783-787.

Xie Y, McGill MR, Cook SF, Sharpe MR, Winefield RD, Wilkins DG, Rollins DE, and Jaeschke $\mathrm{H}(2015)$ Time course of acetaminophen-protein adducts and acetaminophen metabolites in circulation of overdose patients and in HepaRG cells. Xenobiotica 45:921-929.

Xie Y, McGill MR, Dorko K, Kumer SC, Schmitt TM, Forster J, and Jaeschke H(2014) Mechanisms of acetaminophen-induced cell death in primary human hepatocytes. Toxicol Appl Pharmacol 279:266-274.

Yoon E, Babar A, Choudhary M, Kutner M, and Pyrsopoulos N(2016) Acetaminophen-induced hepatotoxicity: a comprehensive update. J Clin Transl Hepatol 4:131-142.

Address correspondence to: Dr. Xiao-bo Zhong, Department of Pharmaceutical Sciences, School of Pharmacy, University of Connecticut, 69 N Eagleville Road, Storrs, CT 06269. E-mail: xiaobo.zhong@uconn.edu 